\title{
Atividade alelopática de óleos essenciais de plantas medicinais na germinação e vigor de aquênios de alface
}

\author{
Allelopathic activity of medicinal plant essential oils on seed \\ germination and vigor of lettuce achenes
}

\author{
Cíntia Alvarenga Santos Fraga Miranda ${ }^{1}$; Maria das Graças Cardoso ${ }^{2 *}$; \\ Maria Laene Moreira Carvalho ${ }^{3}$; Samísia Maria Fernandes Machado ${ }^{4}$; \\ Marcos de Souza Gomes ${ }^{5}$; Juliana de Andrade Santiago ${ }^{6}$; Maria Luisa Teixeira ${ }^{6}$
}

\begin{abstract}
Resumo
Os óleos essenciais vêm despertando interesse comercial na área agrícola, principalmente por suas propriedades alelopáticas, inseticidas, antifúngicas, antimicrobianas e antioxidantes, e, por serem compostos naturais, geralmente, de reduzida toxicidade, custo relativamente baixo e que se degradam rapidamente no ambiente. As plantas medicinais se destacam como potenciais fornecedores de óleos essenciais por sua utilização etnofarmacológica já explorada. O objetivo desta pesquisa foi avaliar o potencial alelopático dos óleos essenciais extraídos de folhas frescas de capim-limão (Cymbopogon citratus), alfavaca (Ocimum gratissimum L.) e manjericão (Ocimum basilicum L.), comparando-os com seus constituintes majoritários (citral, eugenol e cineol, respectivamente), em diferentes formas de aplicação (contato direto e efeito volátil), sobre a germinação e o vigor de aquênios de alface (cultivar Regina SF 3500). Os efeitos dos óleos e seus componentes majoritários foram avaliados pelas variáveis: primeira contagem de germinação, germinação, IVG (índice de velocidade de germinação), massa seca de plântulas e comprimentos médios de parte aérea e radicular de plântulas. Os óleos essenciais de capim-limão e alfavaca apresentaram potenciais alelopáticos sobre a germinação e o vigor de aquênios de alface que podem ser atribuídos aos conteúdos dos respectivos constituintes majoritários, citral e o eugenol, enquanto que o efeito alelopático do óleo essencial de manjericão é consequência do efeito conjunto de todos os componentes do mesmo, independente da metodologia de aplicação.
\end{abstract}

Palavras-chave: Óleos voláteis, Cymbopogon citratus, Ocimum gratissimum L., Ocimum basilicum L., alelopatia

\begin{abstract}
In recent years, essential oils have gained commercial interest in the agricultural area, mainly for their allelopathic, insecticidal, antifungal, antimicrobial and antioxidant properties, and, also for their natural compounds, which have generally displayed low toxicity, relatively low cost and rapid degradation
\end{abstract}

\footnotetext{
${ }^{1}$ Farmacêutica Bioquímica, Pós Doutoranda, Dr ${ }^{\mathrm{a}}$ em Agroquímica, Universidade Federal de Lavras, UFLA, Lavras, MG. E-mail: cintiafmiranda@yahoo.com.br

${ }^{2}$ Bióloga, Prof ${ }^{a}$ Titular, Dr ${ }^{\mathrm{a}}$ em Ciências, UFLA, Lavras, MG. E-mail: mcardoso@dqi.ufla.br

${ }^{3}$ Eng $^{\mathrm{a}}$ Agr $^{\mathrm{a}}$, Prof ${ }^{\mathrm{a}}$ Titular, Dra em Fitotecnia, UFLA, Lavras, MG. E-mail: mlaene@hotmail.com

${ }^{4}$ Química, Prof ${ }^{\mathrm{a}}$ Associado, Dr ${ }^{\mathrm{a}}$ em Química, Universidade Federal de Sergipe, UFS, Aracaju, SE. E-mail: samisiamachado@ yahoo.com.br

${ }^{5}$ Químico Industrial, Pós Doutorando, Dr. em Agroquímica, UFLA, Lavras, MG. E-mail: marcosopq@yahoo.com.br

${ }^{6}$ Químicos, Discentes do Curso de Doutorado em Agroquímica, UFLA, Lavras, MG. E-mail: juandrade_quimica@yahoo.com.br; teixeira_ml@hotmail.com

* Autor para correspondência
} 
in the environment. Medicinal plants have emerged as potential suppliers of essential oils because of their ethnopharmacological utility. The aim of this study was to evaluate the allelopathic potential of essential oils extracted from fresh leaves of lemon grass (Cymbopogon citratus), wild basil (Ocimum gratissimum L.) and sweet basil (Ocimum basilicum L.) with regard to their major constituents (citral, eugenol and cineol, respectively) in different application forms (direct contact and the effect of volatile constituents) on the germination and vigor of lettuce seeds (cultivar Regina SF 3500). The effects of the oils and their major components were evaluated with regard to the variables: first germination count, total germination, GVI (germination velocity index), seedling dry weight and average lengths of shoots and lettuce roots. The essential oils from lemon grass and basil displayed allelopathic potentials on seed germination and vigor of lettuce achenes that can be assigned to their respective major constituents citral and eugenol. On the other hand, the allelopathic effect of the essential oil from basil was a consequence of the combined effect of all the components, regardless the application method.

Key words: Volatile oils, Cymbopogon citratus, Ocimum gratissimum L., Ocimum basilicum L., allelopathy

\section{Introdução}

O efeito de óleos essenciais aplicados em aquênios de diversas espécies agrícolas vem sendo pesquisado pelo seu possível efeito alelopático e pelo seu uso como inseticida (COITINHO et al., 2010), fungicida (GUIMARÃES et al., 2011), bactericida (HUSSAIN et al., 2008) e bioerbicida (SOUZA FILHO; GUILHON; SANTOS, 2010).

A alelopatia é um mecanismo em que as plantas vivas ou mortas liberam alguns tipos de compostos que podem exercer efeito negativo ou positivo sobre outras plantas, desempenhando papel fundamental nos ecossistemas naturais e administrados. Para descobrir as possibilidades dos efeitos alelopáticos na agricultura, o isolamento de novos compostos é a alternativa mais viável e promissora (LI et al., 2011).

Dentre os compostos utilizados pelo seu efeito alelopático, os bioerbicidas se destacam pela grande contribuição que podem trazer para uma agricultura sustentável. O controle de plantas daninhas tem sido realizado principalmente por herbicidas que, embora eficientes do ponto de vista funcional, são questionados quanto aos efeitos tóxicos adversos sobre o meio ambiente, saúde pública e a vida silvestre (SOUZA FILHO et al., 2006). Desse modo, a investigação de compostos naturais como substitutos aos herbicidas sintéticos é de essencial importância para minimizar esses efeitos.
Os bioerbicidas podem ser extraídos de óleos essenciais, que são metabólitos secundários obtidos exclusivamente de vegetais, geralmente odoríferos e constituídos por misturas complexas de inúmeros compostos voláteis tendo, normalmente, um ou dois compostos majoritários. A composição desses óleos voláteis é determinada geneticamente, podendo variar de acordo com origem botânica, quimiotipo, ciclo vegetativo, condições edafoclimáticas e método de obtenção (SIMÕES et al., 2007).

Entre as plantas produtoras de óleos essenciais, destacam-se as plantas medicinais com propriedades antimicrobianas, antifúngicas e antioxidantes. Os óleos essenciais de capim-limão (Cymbopogon citratus Stapf) tiveram suas propriedades fungitóxicas constatadas nas pesquisas realizadas por Guimarães et al. (2011), enquanto os estudos de Pereira e Maia (2007) com óleo essencial de alfavaca (Ocimum gratissimum L.) comprovaram seu intenso potencial antioxidante. Além desses potenciais, o efeito volátil do óleo essencial de alfavaca sobre a germinação e comprimento das raízes de alface (Lactuca sativa L.) foi avaliado por Alves et al. (2004) que constataram que o aumento da concentração do mesmo reduziu o percentual de germinação e o comprimento das radículas. Hussain et al. (2008) avaliaram também as atividades antimicrobianas do óleo volátil de manjericão (Ocimum basilicum L.) e verificaram ação eficiente do mesmo contra os fungos e as 
bactérias analisados. Já Rosado et al. (2009) avaliaram o efeito volátil desse óleo essencial sobre a germinação e verificaram que o mesmo apresentou potencialidades alelopáticas inibitórias em sementes de alface, de tomate e de melissa afetando o índice de velocidade de germinação, o comprimento das raízes e a porcentagem de germinação. Esses autores destacaram a possibilidade do monoterpeno linalol, composto majoritário presente no manjericão, ser o responsável pelos efeitos fitotóxicos nas sementes e no crescimento inicial das plântulas das espécies avaliadas. Os efeitos do contato direto desses óleos essenciais e as análises comparativas específicas dos compostos majoritários sobre a germinação e vigor de alface não foram efetuadas por nenhum dos autores citados.

Os potenciais alelopáticos de óleos essenciais, usualmente, são avaliados por duas metodologias. A primeira analisa o efeito volátil das soluções dos óleos sobre a germinação dos aquênios e/ou desenvolvimento das plântulas, como demonstrado por Silva et al. (2009), ao constatar os efeitos aleloquímicos do óleo volátil da erva-de-capitão (Hydrocotyle bonariensis Lam.) em aquênios de alface e cebola (Allium cepa). A segunda avalia o contato direto das soluções dos óleos essenciais, quando adicionadas ao substrato, como observado por Souza Filho et al. (2009). Esses autores realizaram uma análise comparativa do potencial alelopático do extrato hidroalcoólico e do óleo volátil de folhas de cipó-d’alho (Mansoa standleyi (Steyerm.) A.H.Gentry) em aquênios de malícia (Mimosa pudica L.), constatando maior potencialidade do extrato em inibir a germinação, enquanto o desenvolvimento da raíz e hipocótilo foi mais afetado pelo óleo essencial.

$\mathrm{Na}$ pesquisa de substâncias com potencial bioerbicida a espécie mais utilizada nesses bioensaios como planta indicadora é a alface, pois de acordo com Souza Filho, Guilhon e Santos (2010) essa espécie é extremamente sensível aos efeitos dos aleloquímicos, demonstrando até mesmo pequenos sinais de fitotoxidez. Ainda de acordo com esses autores, o mecanismo de ação dos óleos voláteis é desconhecido, não se sabe como seus constituintes atuam e se ocorre algum sinergismo nessa ação. Adicionalmente, o potencial alelopático dos óleos essenciais sobre a germinação de aquênios e desenvolvimento de plantas é frequentemente atribuído, de maneira não comprovada, aos constituintes majoritários ou determinadas classes de compostos químicos presentes nos mesmos. A composição química variável dos óleos essenciais em relação a seus constituintes majoritários, bem como a ação isolada de cada composto, dificilmente é relatada na literatura, o que enfatiza a importância da pesquisa sobre a ação conjunta ou individual dos compostos em sua ação alelopática.

Diantedoexposto, objetivou-seavaliaropotencial alelopático dos óleos essenciais extraídos de folhas frescas de capim-limão, alfavaca, manjericão, comparando-os com seus constituintes majoritários (citral, eugenol e cineol, respectivamente), por diferentes formas de aplicação (contato direto e efeito volátil) na germinação e vigor de aquênios de alface.

\section{Material e Métodos}

As espécies vegetais capim-limão, alfavaca e manjericão foram coletadas no município de Lavras/MG, no Horto de Plantas Medicinais da Universidade Federal de Lavras, e as exsicatas foram depositadas no Herbário ESAL na UFLA, sob os registros de numeração 18409, 07045 e 18406, respectivamente. As espécies foram coletadas no início da manhã de dias quentes, sem precipitação pluvial e as partes utilizadas foram, somente, folhas jovens (nervura e limbo de folhas simples completamente expandidas), sem injúrias, de plantas adultas (aproximadamente 6 meses à campo) no estágio de floração plena.

As folhas frescas picadas (300 gramas) foram submetidas ao processo de extração dos óleos essenciais por hidrodestilação, utilizando um 
aparelho de Clevenger modificado e adaptado a um balão de fundo redondo com capacidade de 4 litros, por um período de 2 horas conforme metodologia descrita por Guimarães et al. (2008). O material obtido foi centrifugado por 5 minutos e, posteriormente, os óleos voláteis foram acondicionados em frasco de vidro âmbar e armazenados, no escuro, em geladeira a $15^{\circ} \mathrm{C}$.

A determinação do teor de água das folhas foi realizada paralelamente à extração dos óleos essenciais, de acordo com método descrito por Pimentel et al. (2006). Em um balão volumétrico com capacidade de $0,25 \mathrm{~L}$ acoplado a um condensador com coletor volumetricamente graduado, foram colocados $5 \mathrm{~g}$ de folhas frescas picadas dos referidos vegetais em $0,07 \mathrm{~L}$ de cicloexano. $\mathrm{O}$ balão foi colocado sobre manta aquecedora por 2 horas, a temperatura de $81 \pm 1^{\circ} \mathrm{C}$ e o volume de água medido para o cálculo do rendimento das extrações (em base seca).

A avaliação qualitativa do óleo essencial foi realizada por cromatografia em fase gasosa acoplada à espectrometria de massa (CG/EM Shimadzu, modelo QP 5050A). A identificação dos constituintes foi realizada com base na comparação dos índices de retenção da literatura (ADAMS, 2007). Para o índice de retenção foi utilizado a equação de Van den Dool e Kratz (1963) em relação à série homóloga de alcanos lineares $\left(\mathrm{nC}_{8}-\mathrm{nC}_{18}\right)$ e fazendo extrapolação para $\mathrm{C}_{19}$ e $\mathrm{C}_{20}$. Também foram utilizadas duas bibliotecas do equipamento NIST107 e NIST21 para a comparação dos dados dos espectros. Na avaliação quantitativa utilizouse um cromatógrafo gasoso Shimadzu CG-17A equipado com detector por ionização de chamas (DIC), sendo a quantificação de cada constituinte obtida por meio de normalização de áreas (\%).

De posse dos óleos essenciais extraídos realizaram-se dois bioensaios: o primeiro avaliando o efeito volátil e, o segundo, o contato direto dos óleos essenciais e dos padrões de seus constituintes majoritários sobre a germinação dos aquênios de alface (cultivar: Regina SF 3.500). Para o preparo das soluções $0,5 \mathrm{~g}$ de cada óleo essencial ou constituinte majoritário foi emulsionado com Tween 80, na proporção $1: 1(\mathrm{v} / \mathrm{v})$ e dissolvido em água destilada (q.s.p. $100 \mathrm{~mL}$ de solução), obtendose a solução estoque na concentração de $1 \%$. As demais concentrações $(0,5 ; 0,25 ; 0,12 ; 0,05 \%$ em $\mathrm{v} / \mathrm{v}$ ) foram preparadas por diluição. Como controles foram utilizados uma solução de Tween 80 a 1,0\% v/v e água (SILVA et al., 2009). As soluções testadas foram adicionadas apenas no início dos bioensaios, e posteriormente, quando necessário, apenas água destilada foi acrescentada (SOUZA FILHO et al., 2009).

Em ambos os bioensaios os aquênios foram acondicionadas em caixa acrílica tipo gerbox (dimensões $11 \times 11 \times 4 \mathrm{~cm}$ ), tendo como substrato duas folhas de papel mata-borrão esterilizadas. Em cada gerbox, foram distribuídos 100, totalizando 400 aquênios por tratamento e esses foram mantidos em câmara de crescimento (BOD) à temperatura de $20 \pm 1{ }^{\circ} \mathrm{C}$ e fotoperíodo de 12 horas. $\mathrm{Na}$ metodologia do contato direto, o papel mata-borrão foi embebido, com quantidades equivalentes a 2,5 vezes a sua massa seca, com soluções de diferentes concentrações (BRASIL, 2009). Para avaliação do efeito volátil, foi adicionada água destilada ao substrato de papel em quantidades equivalentes a 2,5 vezes a sua massa seca (BRASIL, 2009). Adicionalmente $3 \mathrm{~mL}$ das soluções foram colocados em duas folhas de papel de filtro afixados na tampa do gerbox, evitando contato direto da solução testada com os aquênios (SOUZA FILHO et al., 2009).

A germinação foi monitorada por sete dias, contados a partir da implantação do ensaio, com contagens diárias das plântulas de alface (iniciando com a protrusão da radícula), sendo os resultados expressos em porcentagem de plântulas normais (BRASIL, 2009).

O vigor dos aquênios foi determinado pelas seguintes variáveis: 
Primeira contagem de germinação que constou da avaliação no quarto dia após a semeadura, de plântulas normais (plântulas que apresentaram estruturas vegetativas perfeitas) (BRASIL, 2009); Índice de Velocidade de Germinação (IVG), calculado segundo Maguire (1962); Comprimentos médios de raiz e de parte aérea das plântulas ao sétimo dia, realizado com auxílio de régua milimetrada sendo os resultados médios expressos em centímetros (BRASIL, 2009); Determinação da massa seca de plântulas realizada em estufa a $60^{\circ} \mathrm{C}$, em embalagens de papel Kraft, até obtenção de massas constantes. Depois desse período, efetuouse a pesagem e determinação das médias por repetição, sendo os resultados expressos em gramas (KRZYZANOWSKI, VIEIRA; FRANÇA NETO, 1999).

Em cada uma das espécies vegetais estudadas, o delineamento experimental utilizado para ambas as metodologias foi inteiramente casualizado em esquema fatorial $6 \times 2$ (concentrações $\mathrm{x}$ óleo essencial + constituinte majoritário), com quatro repetições. Os óleos essenciais extraídos de diferentes espécies não foram comparados entre si por se tratarem de constituições químicas diferentes. Da mesma forma não houve comparação entre as diferentes metodologias. Os fatores quantitativos significativos pelo teste de $\mathrm{F}$ $(p<0,05)$ foram submetidos à análise de regressão para determinação dos modelos.

\section{Resultados e Discussão}

Os rendimentos das extrações dos óleos essenciais das espécies vegetais foram distintos, sendo o da alfavaca de $2,1 \%$, o do manjericão de $1,4 \%$ e o do capim-limão de $0,7 \%$ (todos em p/p em Base Livre de Umidade). Já os teores de água das folhas das plantas foram de $78 \%$ para a alfavaca e o manjericão e de $72 \%$ para o capim-limão. Os constituintes majoritários dos óleos voláteis e seus respectivos percentuais estão apresentados na Tabela 1, destacando-se o geranial, neral e mirceno para o capim-limão; eugenol, $\beta$-ocimeno e muuruleno, para a alfavaca e; 1,8-cineol, linalol e cânfora para o manjericão.

O contato direto do óleo essencial de capim-limão e seu componente principal, o monoterpeno citral (mistura isomérica do neral e geranial) provocaram completo impedimento da germinação a partir de $0,25 \%$, enquanto que, para as concentrações inferiores, o citral apresentou maior velocidade na redução das respostas destas variáveis e total inibição das mesmas já na concentração de $0,12 \%$ (Figura 1). Na avaliação dos efeitos voláteis de óleo essencial de capimlimão e do citral sobre as variáveis analisadas, o constituinte majoritário demonstrou efeito tóxico mais expressivo que o respectivo óleo essencial (Figura 2).

De acordo com os resultados verificados em ambas as metodologias empregadas, infere-se que o efeito alelopático do óleo essencial de capimlimão deve-se ao conteúdo de seu componente principal, o citral. Ao avaliarem os efeitos voláteis dos óleos essenciais de folhas de capim-limão coletadas no Ceará, nas concentrações de 0 ; 0,$001 ; 0,01 ; 0,1$ e $1 \%$ v/v sobre a germinação e comprimento da raiz de plântulas de alface, Alves et al. (2004) verificaram uma crescente redução da resposta destas variáveis em função do aumento da concentração, com morte da plântula a partir da concentração $0,1 \%$. Esta divergência observada entre a fitotoxidez dos óleos essenciais de uma mesma espécie vegetal pode ser justificada pelas divergências entre as composições químicas dos mesmos, que ocorrem devido às diferenças entre os locais de origem e fatores edafoclimáticos (GOBBO-NETO; LOPES, 2007). 
Tabela 1. Porcentagem e índice de retenção dos constituintes dos óleos essenciais de capim-limão, alfavaca e manjericão.

\begin{tabular}{|c|c|c|c|c|}
\hline \multirow{2}{*}{ Constituintes } & \multirow{2}{*}{ IR cal } & \multicolumn{3}{|c|}{$\%$ dos constituintes } \\
\hline & & Capim-limão & Alfavaca & Manjericão \\
\hline$(\alpha)$-tujeno & 924 & - & 0,11 & - \\
\hline$(\alpha)$-pineno & 931 & - & - & 0,64 \\
\hline canfeno & 947 & - & - & 0,53 \\
\hline sabineno & 970 & - & 0,16 & 0,63 \\
\hline$(\beta)$-pineno & 975 & - & - & 1,28 \\
\hline (6-metil-5) hepten-2-ona & 983 & 0,99 & - & - \\
\hline mirceno & 988 & 2,07 & - & 0,81 \\
\hline limoneno & 1027 & - & - & 1,13 \\
\hline 1,8-cineol & 1031 & - & - & 20,86 \\
\hline (Z)- $\beta$-ocimeno & 1035 & - & 7,99 & - \\
\hline (E)- $\beta$-ocimeno & 1045 & - & 0,36 & 0,14 \\
\hline$(\gamma)$-terpineno & 1057 & - & - & 0,08 \\
\hline sabineno hidratado & 1069 & - & - & 1,03 \\
\hline terpinoleno & 1084 & - & - & 0,28 \\
\hline fenchona & 1087 & - & - & 0,82 \\
\hline$(6,7)$-epoximirceno & 1090 & 0,42 & - & - \\
\hline linalol & 1100 & - & - & 16,58 \\
\hline cânfora & 1146 & - & - & 14,72 \\
\hline$(\gamma)$-terpineol & 1169 & - & - & 0,66 \\
\hline terpinen-4-ol & 1179 & - & 0,31 & 0,60 \\
\hline$\alpha$-terpineol & 1194 & - & - & 4,24 \\
\hline neral & 1238 & 29,78 & - & - \\
\hline geraniol & 1250 & 0,43 & - & - \\
\hline geranial & 1268 & 41,61 & - & - \\
\hline acetato de isobornil & 1283 & - & - & 0,22 \\
\hline (2)-undecanona & 1292 & 1,16 & - & - \\
\hline acetato de mirtenil & 1322 & - & - & 0,11 \\
\hline nerolato de etila & 1355 & 0,77 & - & - \\
\hline eugenol & 1357 & - & 77,97 & 10,50 \\
\hline$(\alpha)$-copaeno & 1374 & - & - & 0,13 \\
\hline acetato de geranila & 1377 & 0,37 & - & - \\
\hline ( $\beta$ )-bourboneno & 1382 & - & - & 0,19 \\
\hline ( $\beta$ )-elemeno & 1387 & - & - & 0,29 \\
\hline (E)-cariofileno & 1418 & - & 1,26 & 1,37 \\
\hline$(\alpha)$-trans-bergamoteno & 1431 & - & - & 1,98 \\
\hline$(\alpha)$-humuleno & 1454 & - & - & 0,34 \\
\hline cis-candina-1(6),4-dieno & 1460 & - & - & 0,19 \\
\hline propanoato de geranila & 1468 & - & - & - \\
\hline$(\gamma)$-muuruleno & 1480 & - & 6,03 & - \\
\hline (2)-tridecanona & 1494 & 1,00 & - & - \\
\hline biciclogermacreno & 1494 & - & - & 0,58 \\
\hline$(\alpha)$-bulneseno & 1500 & - & - & 0,31 \\
\hline$(\gamma)$-cadineno & 1511 & - & - & 1,24 \\
\hline$(\delta)$-cadineno & 1516 & - & - & 0,08 \\
\hline cubebol & 1613 & - & - & 1,09 \\
\hline epi-cadinol & 1640 & - & - & 8,67 \\
\hline
\end{tabular}

IR cal = índice de retenção calculado pela equação de Kovats.

Fonte: Elaboração dos autores. 
Figura 1. Equações de regressão da variável resposta germinação (A), primeira contagem de germinação (B), IVG (C), massa de plântulas secas (D), comprimentos de parte aérea (E) e de raiz (F) em função da concentração do óleo essencial de capim-limão e citral, avaliadas pela metodologia do contato direto.

A

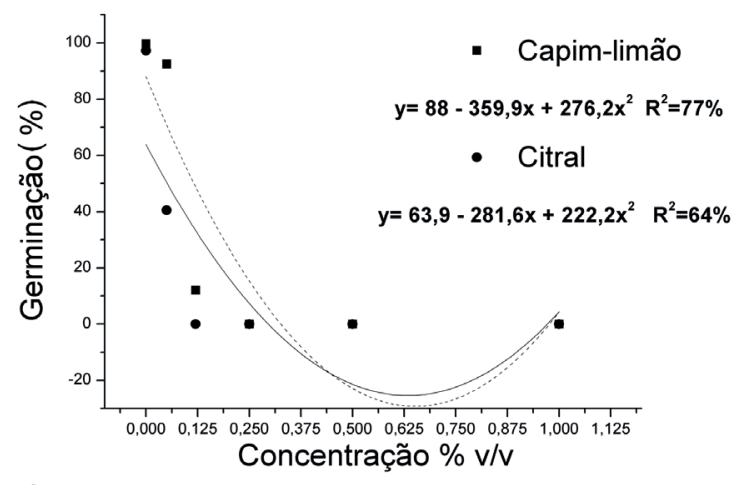

C
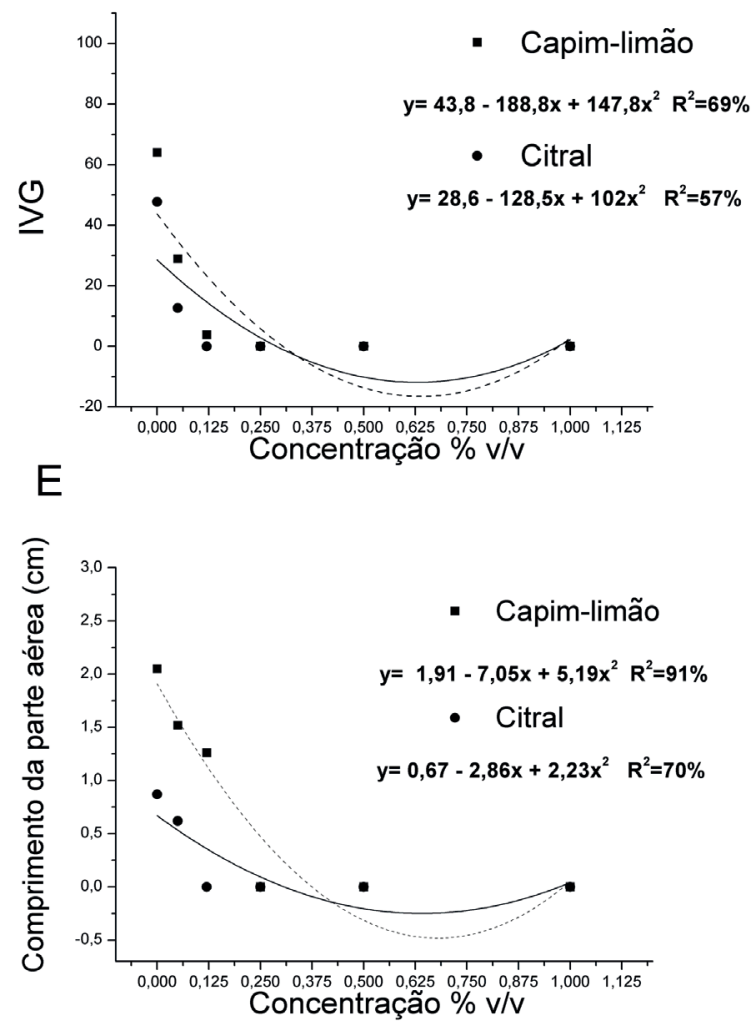

Capim-limão
B

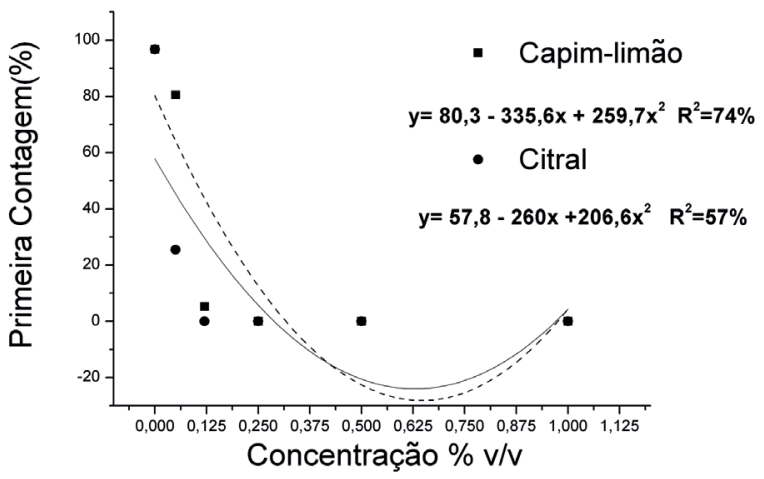

D

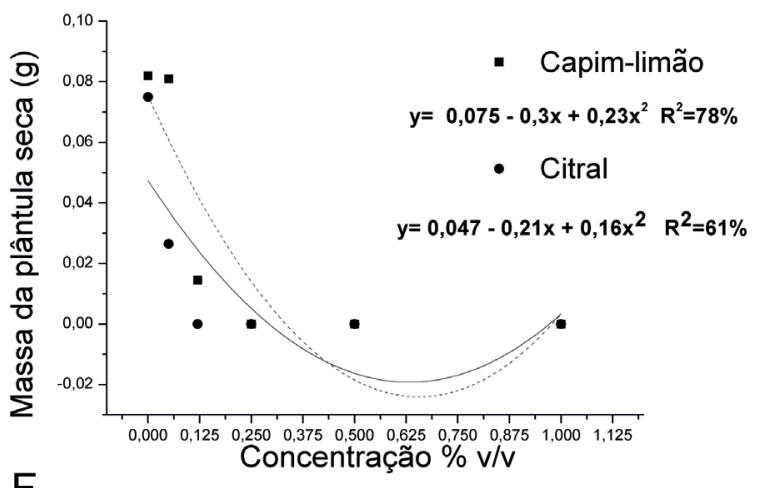

$\mathrm{F}$

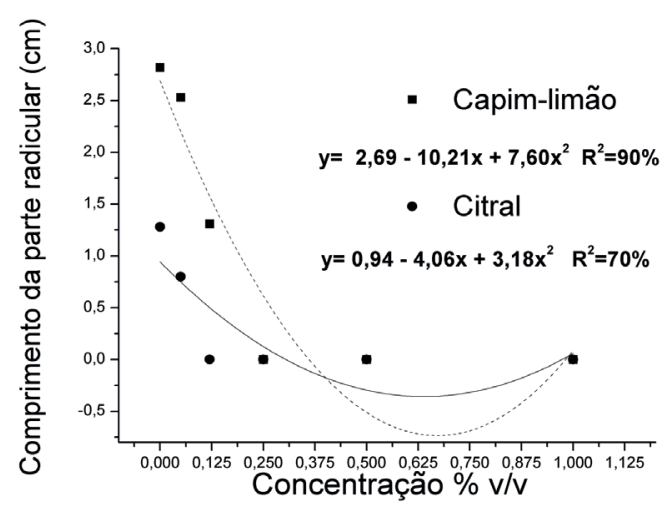

Citral

Fonte: Elaboração dos autores. 
Figura 2. Equações de regressão da variável resposta germinação (A), primeira contagem de germinação (B), IVG (C), massa de plântulas secas (D), comprimentos de parte aérea (E) e de raiz (F) em função da concentração do óleo essencial de capim-limão e citral, avaliadas pela metodologia do efeito volátil.

A

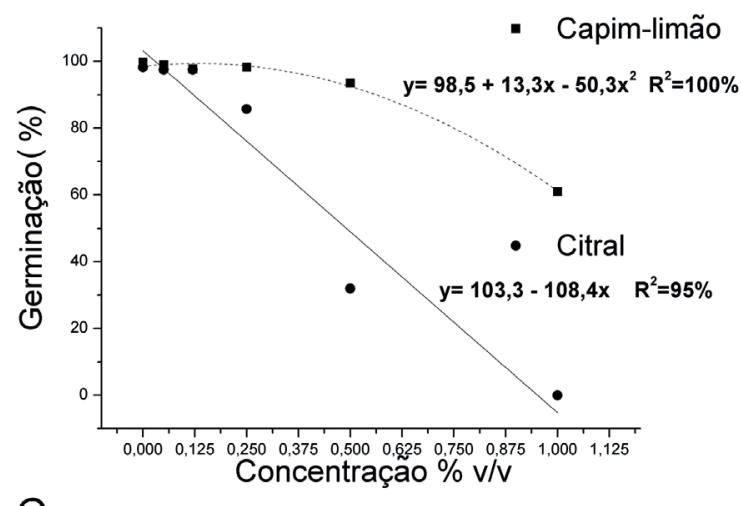

C
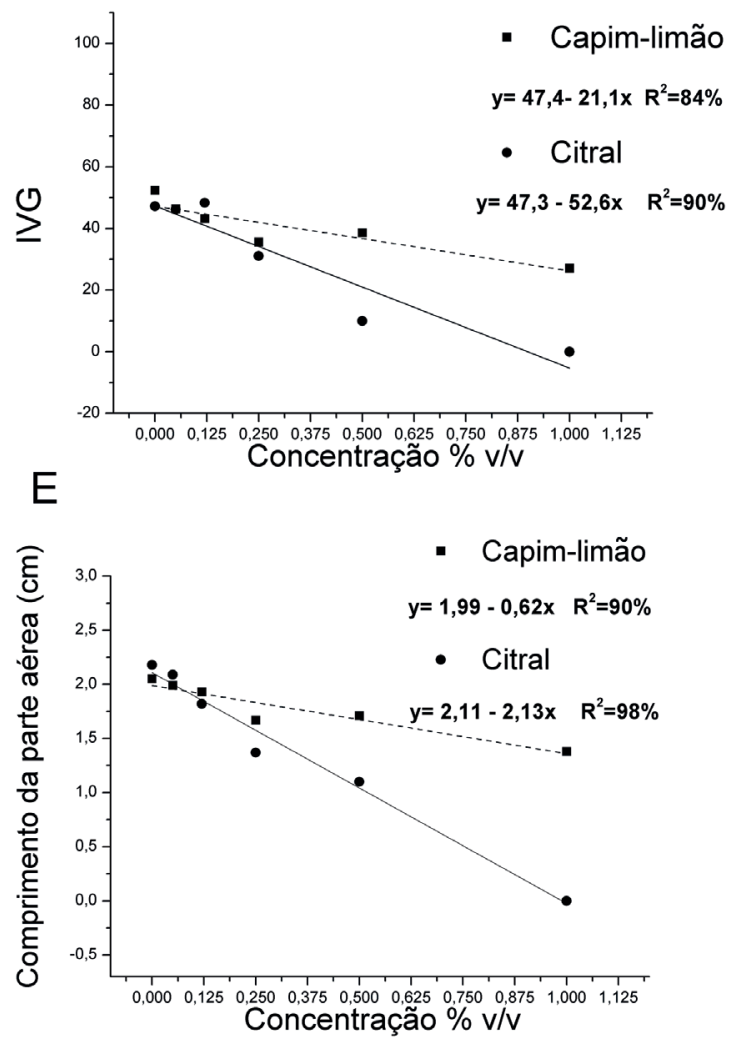

Capim-limão
B

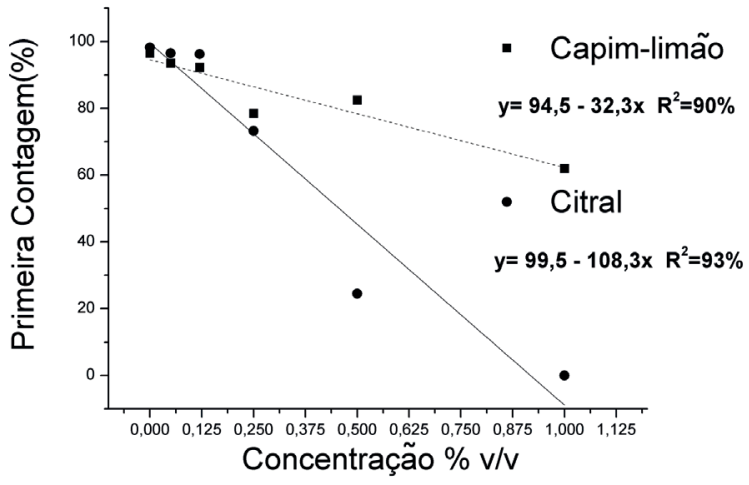

D

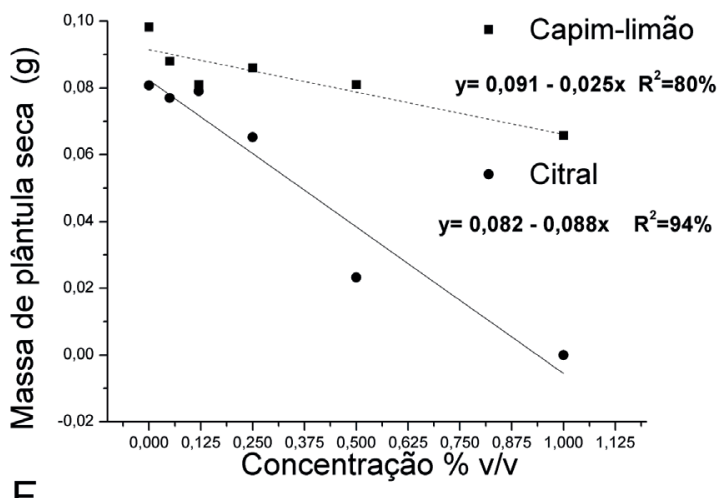

F

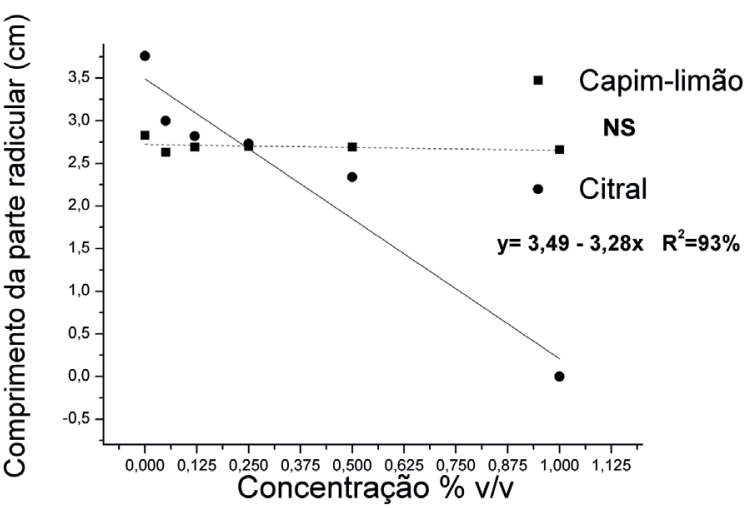

Citral

Fonte: Elaboração dos autores.

O óleo essencial de alfavaca e seu componente majoritário, o fenilpropanoide eugenol, quando em contato direto com os aquênios de alface, apresentaram atividades semelhantes sobre as variáveis estudadas, promovendo intensa redução das respostas a partir da concentração $0,12 \%$, com maior efeito alelopático do eugenol em relação ao respectivo óleo e inibição completa da germinação na concentração de $0,5 \%$ (Figura 3 ). 
Figura 3. Equações de regressão da variável resposta germinação (A), primeira contagem de germinação (B), IVG (C), massa de plântulas secas (D), comprimentos de parte aérea (E) e de raiz (F) em função da concentração do óleo essencial de alfavaca e eugenol, avaliadas pela metodologia do contato direto.

A

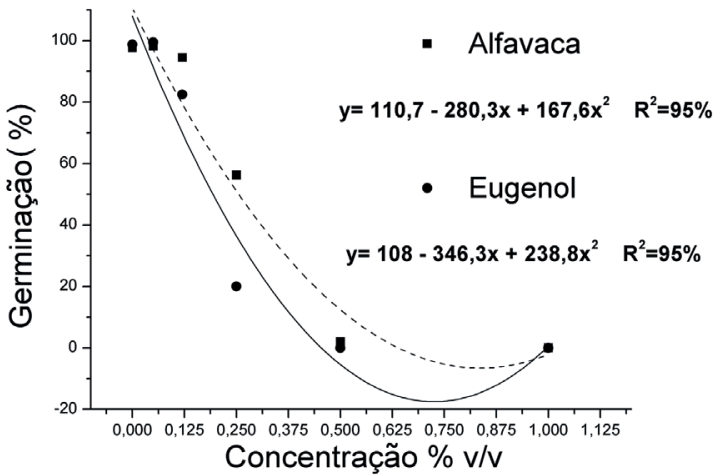

C

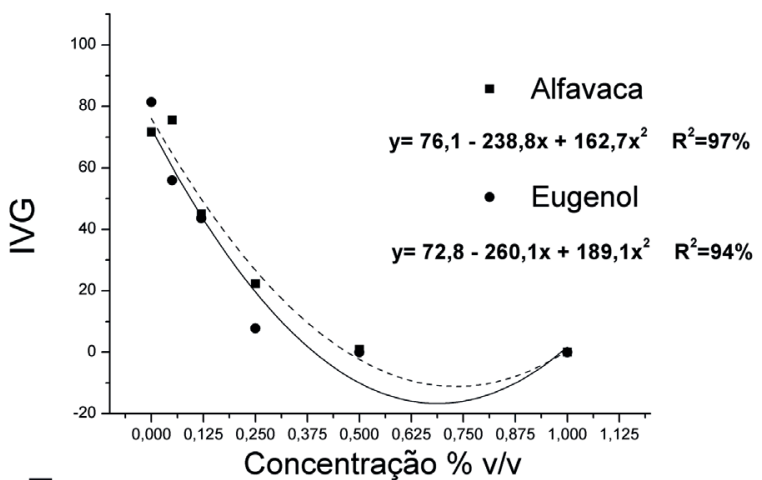

$\mathrm{E}$

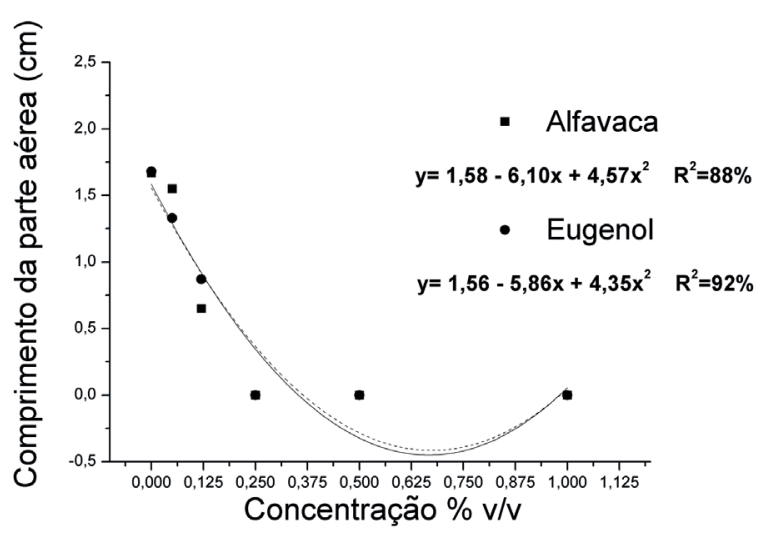

Fonte: Elaboração dos autores.
B

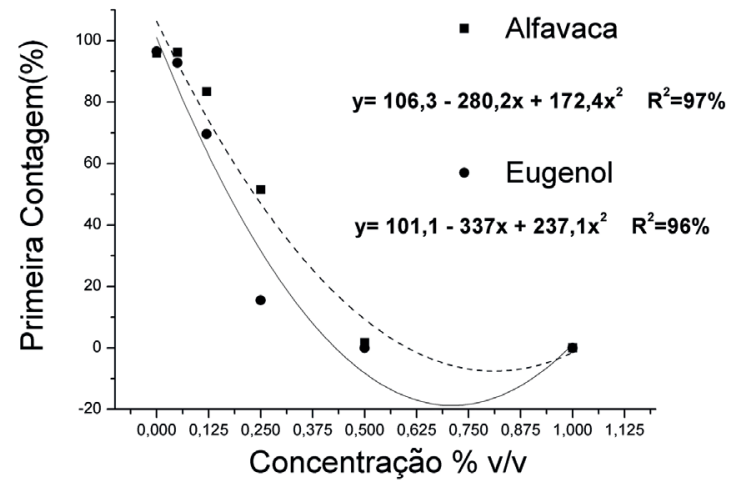

D

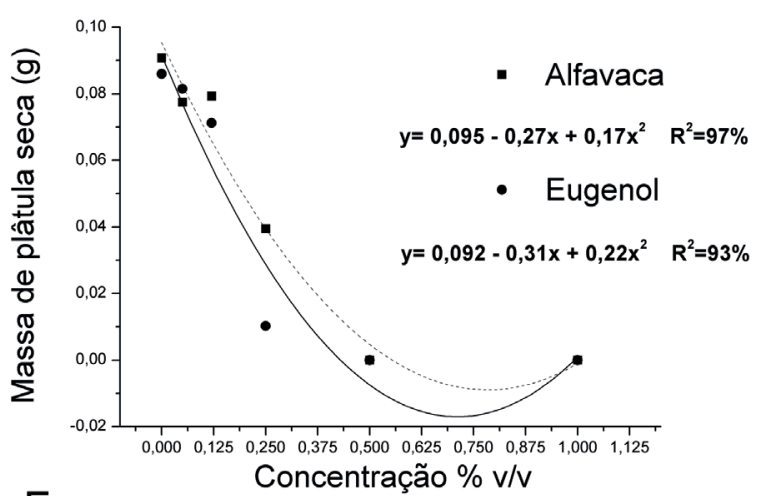

$\mathrm{F}$

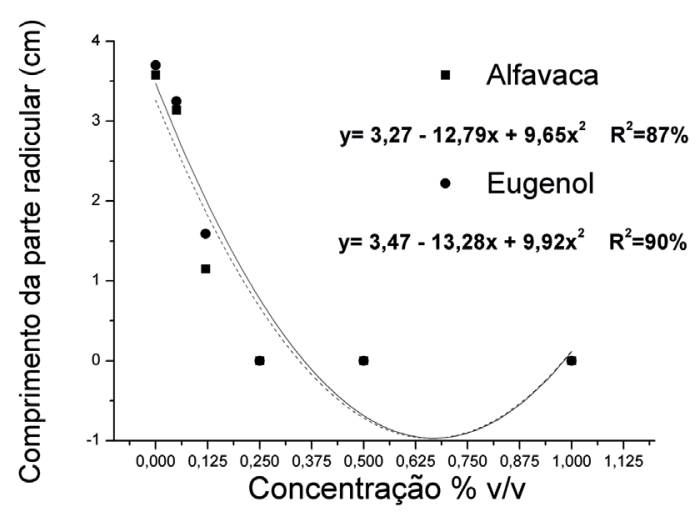

Eugenol

Ao avaliar a influência do efeito volátil sobre a germinação de aquênios e primeira contagem pôdese verificar que o eugenol reduziu essas variáveis, enquanto as respostas do óleo essencial não foram dose-dependentes em relação aos tratamentos testados. As variáveis IVG, massa seca de plântula,

comprimentos das plântulas (parte aérea e raiz) apresentaram menores respostas com o aumento das concentrações do óleo e do constituinte principal, sendo que o eugenol demonstrou efeitos mais pronunciados que o óleo essencial de alfavaca (Figura 4). 
Figura 4. Equações de regressão da variável resposta germinação (A), primeira contagem de germinação (B), IVG (C), massa de plântulas secas (D), comprimentos de parte aérea (E) e de raiz (F) em função da concentração do óleo essencial de alfavaca e eugenol, avaliadas pela metodologia do efeito volátil.
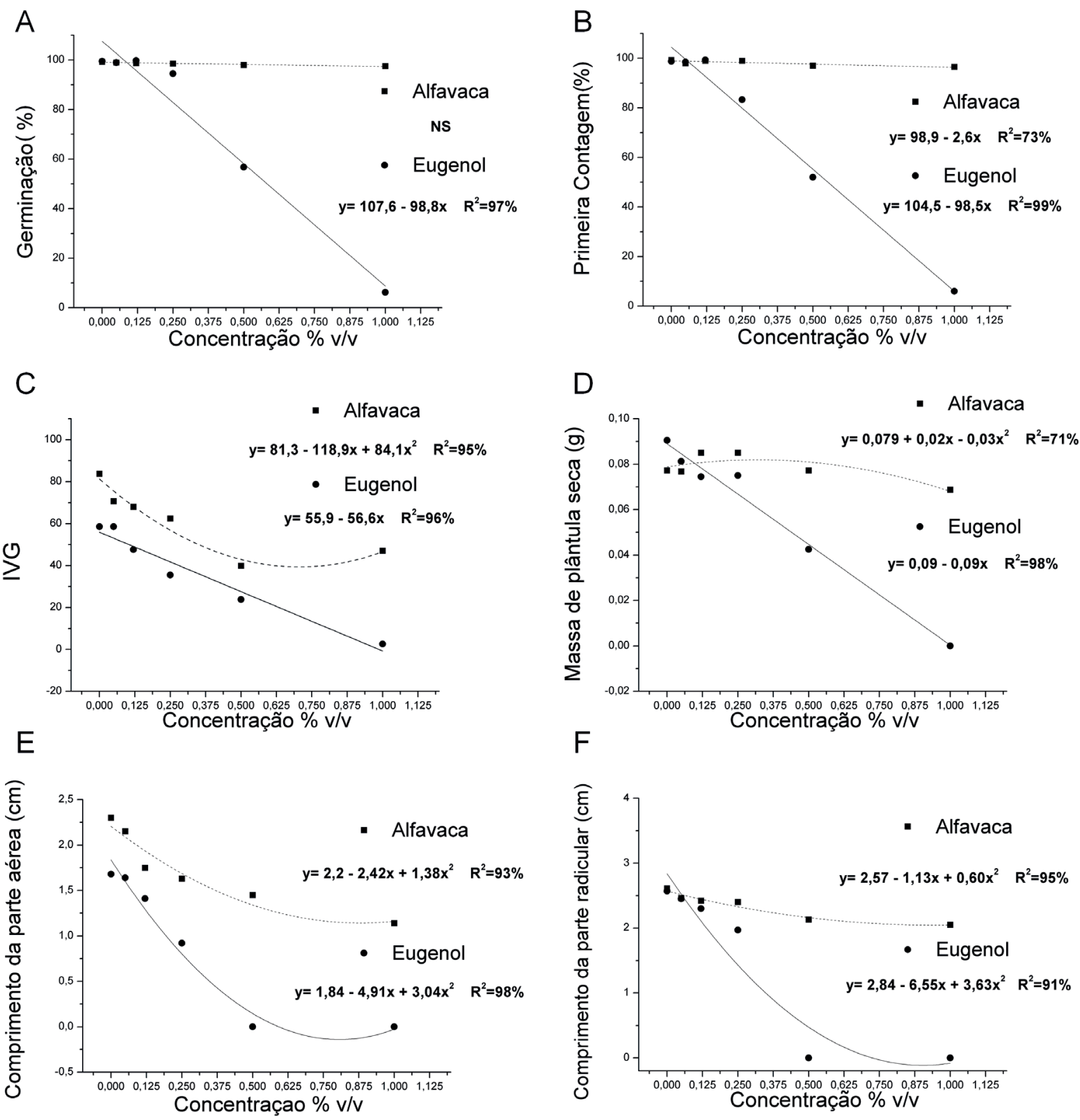

Alfavaca Eugenol

Fonte: Elaboração dos autores.

Pelos resultados observados em ambas as metodologias utilizadas, o efeito alelopático do óleo essencial de alfavaca pôde ser atribuído ao conteúdo do seu componente majoritário, eugenol. Alves et al. (2004), avaliando os efeitos voláteis dos óleos essenciais de alfavaca verificaram que

este apresentou baixa influência na germinação (99 a 90\%) nas menores concentrações e que na concentração de $1 \%$, apresentou inibição total da mesma. Adicionalmente observaram decréscimo no comprimento da raiz (variação de 1,43 a $0,37 \mathrm{~cm}$ ) com o aumento da concentração do óleo essencial. 
A toxidez apresentada por esse óleo essencial coletado no Ceará foi superior à verificada no presente trabalho, fato que possivelmente se deva à variação da composição química dos mesmos, que se relaciona com local de coleta, ciclo vegetativo, fatores da natureza e método de obtenção dos óleos essenciais (SIMÕES et al., 2007).

Os efeitos tóxicos provocados pelo contato direto do óleo essencial do manjericão e de seu componente principal, o monoterpeno cineol, sobre as variáveis analisadas, foram dose dependentes, com exceção da influência do óleo essencial sobre o comprimento de parte aérea das plântulas de alface. Em todas as variáveis analisadas observou-se menor efeito alelopático nas concentrações iniciais testadas e maior decréscimo das respostas a partir da concentração de $0,5 \%$. Adicionalmente observouse que o potencial alelopático do óleo essencial de manjericão foi superior ao do constituinte majoritário (Figura 5).

Analisando os efeitos voláteis do óleo essencial de manjericão observou-se baixa interferência do aumento das concentrações nas respostas das variáveis. Efeitos semelhantes a esses foram verificados ao se analisar os efeitos voláteis do cineol sobre a germinação, primeira contagem e IVG. Adicionalmente, a toxidez apresentada pelo óleo essencial sobre essas variáveis foi discretamente superior ao constituinte majoritário. Entretanto, ao se analisar a influência do cineol sobre a massa seca de plântula e os comprimentos de parte aérea e radicular, verifica-se que o composto provocou redução mais pronunciada das mesmas, quando comparadas ao óleo essencial. Esse fato pode ser explicado pelo incremento das doses do cineol não alterar significativamente a germinação dos aquênios de alface, mas provocar redução da parte aérea e, principalmente, da parte radicular da plântula, o que afeta diretamente a variável massa de plântula seca (Figura 6).

Diante do exposto, o potencial alelopático do óleo essencial de manjericão se deve ao efeito somado de todos os seus constituintes e não somente ao conteúdo do seu composto majoritário, o cineol. O efeito volátil do óleo essencial de folhas de manjericão cultivados em substrato comercial e mantidas em casa de vegetação foi avaliado por Rosado et al. (2009). Os autores analisaram a fitotoxidez desta solução nas concentrações $0 ; 0,001$; 0,$01 ; 0,1$ e $1 \%$ (v/v) sobre germinação e vigor de aquênios de alface, e constataram uma diminuição dos valores de IVG, germinação e comprimento das raízes com o incremento das doses de óleo. Os resultados foram atribuídos, provavelmente, ao linalol, que foi encontrado na proporção de aproximadamente $78 \%$ na constituição do óleo essencial, enquanto que a porcentagem de cineol foi de apenas $1,12 \%$. Desta forma, os resultados do presente experimento divergem dos encontrados pelos autores, que verificaram atividade alelopática mais acentuada do óleo essencial de manjericão. Esta diferença do óleo essencial de manjericão provavelmente ocorreu devido à diferença da constituição química desses, em virtude de suas distintas procedências e condições de cultivo (SIMÕES et al., 2007).

O potencial alelopático de um óleo essencial é frequentemente atribuído ao seu conteúdo de monoterpenos, que afetam a germinação e crescimento de plantas, por causarem modificações morfológicas e fisiológicas nos vegetais, como as inibições da cadeia respiratória da matriz mitocondrial isolada e mitose, alteração da integridade das membranas das células, deterioração das ceras cuticulares, aumento da transpiração, peroxidação lipídica e danos aos microtúbulos (MIRANDA et al., 2014). Diante disso a análise comparativa do potencial fitotóxico dos óleos essenciais e de seus constituintes majoritários individualmente torna-se fundamental.

Os resultados encontrados no presente estudo correlacionando a constituição química e a atividade alelopática de cada óleo essencial e um de seus constituintes majoritários individualmente 
corroboram com as observações feitas por Souza Filho et al. (2009), que afirmaram que os efeitos dos óleos essenciais na germinação e vigor de plântulas não podem ser generalizados, podendo ser explicados de forma individualizada considerando os principais constituintes químicos dos mesmos.

Figura 5. Equações de regressão da variável resposta germinação (A), primeira contagem de germinação (B), IVG (C), massa de plântulas secas (D), comprimentos de parte aérea (E) e de raiz (F) em função da concentração do óleo essencial de manjericão e cineol, avaliadas pela metodologia do contato direto.

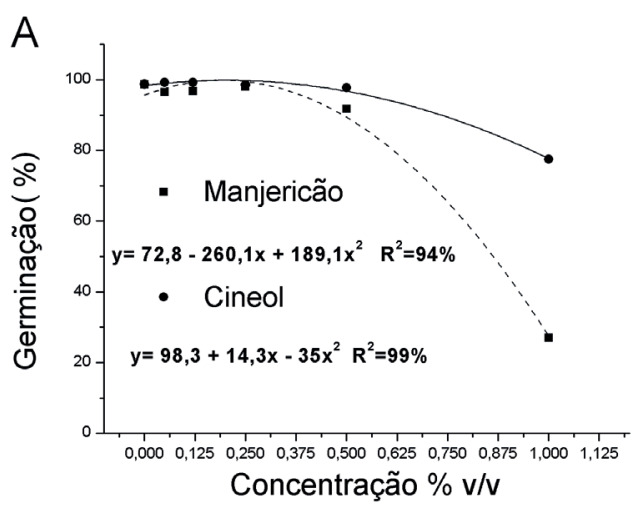

C
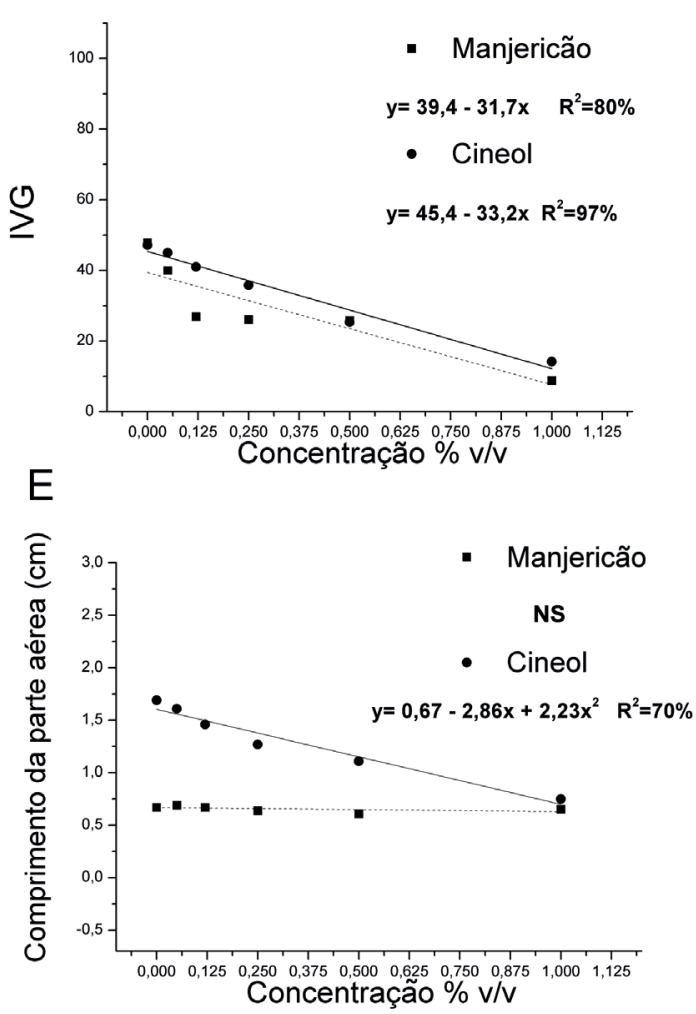

Manjericão
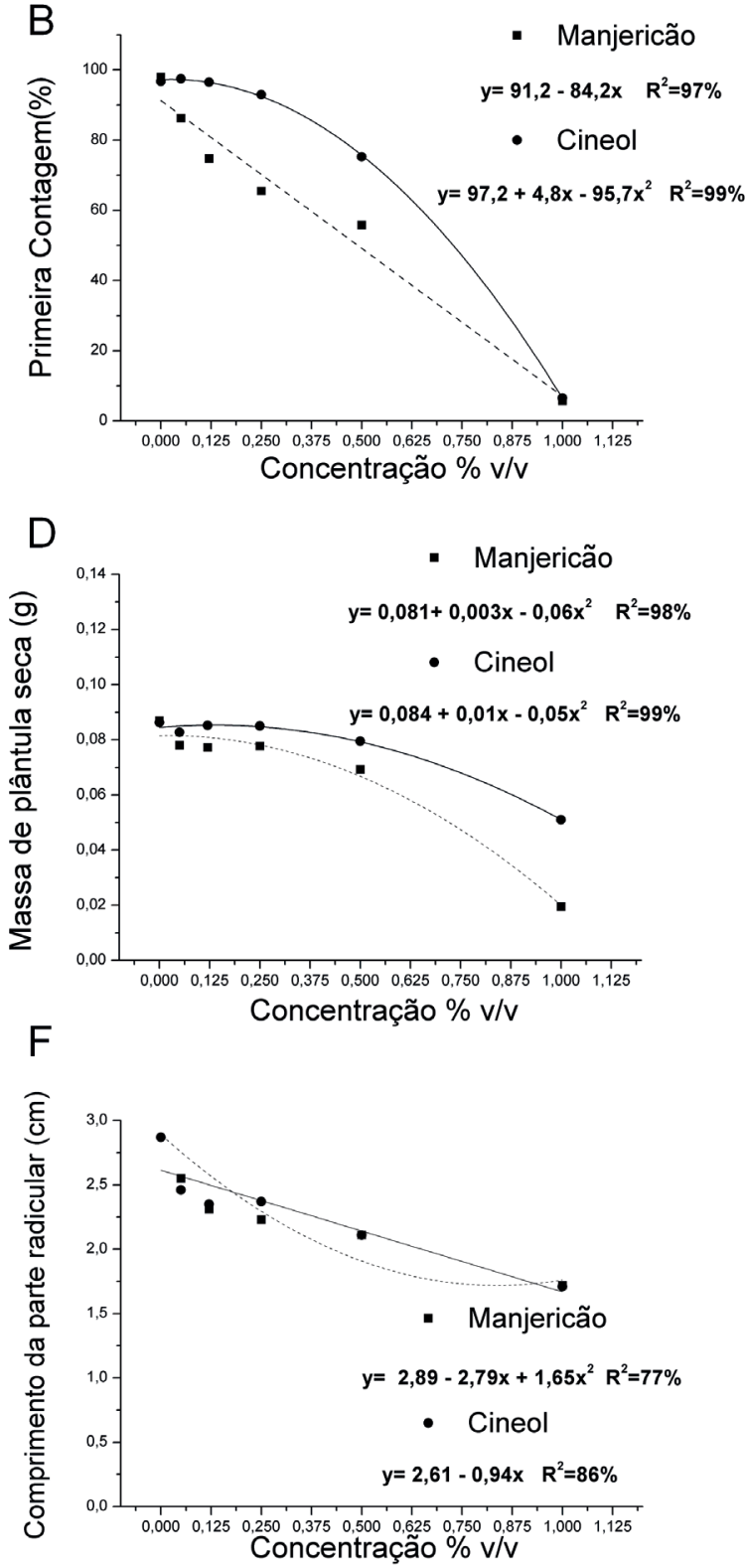

Cineol

Fonte: Elaboração dos autores. 
Figura 6. Equações de regressão da variável resposta germinação (A), primeira contagem de germinação (B), IVG (C), massa de plântulas secas (D), comprimentos de parte aérea (E) e de raiz (F) em função da concentração do óleo essencial de manjericão e cineol, avaliadas pela metodologia do efeito volátil.

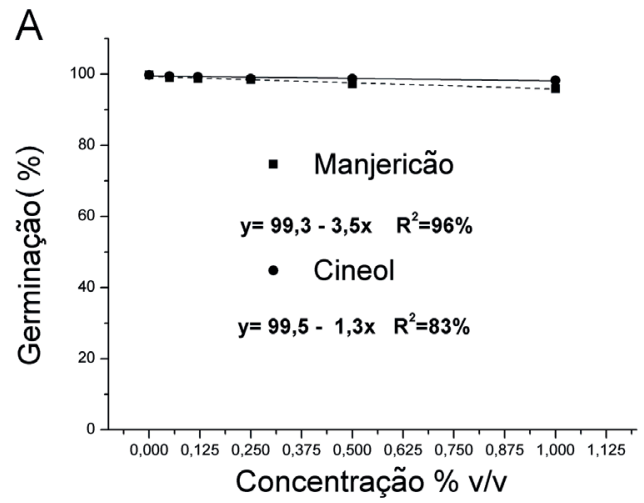

C

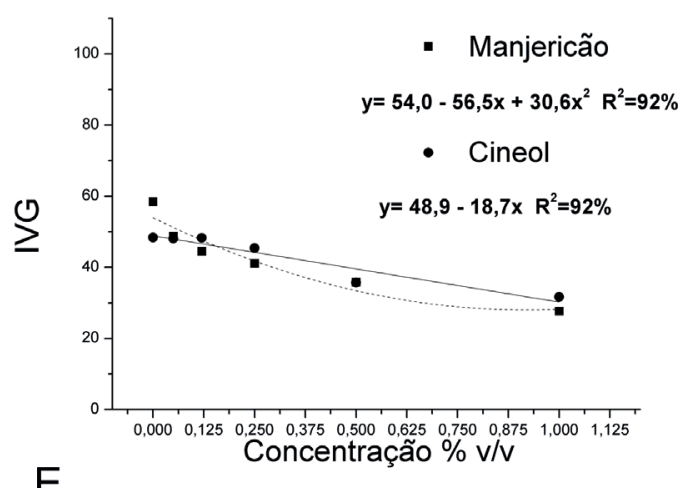

$E$

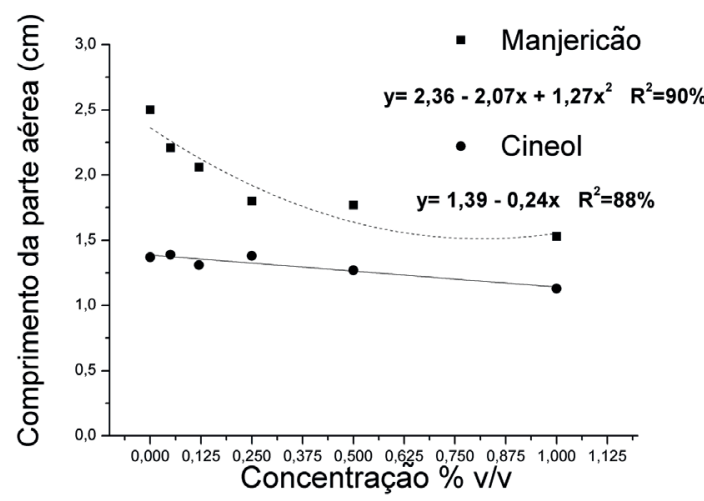

Manjericão
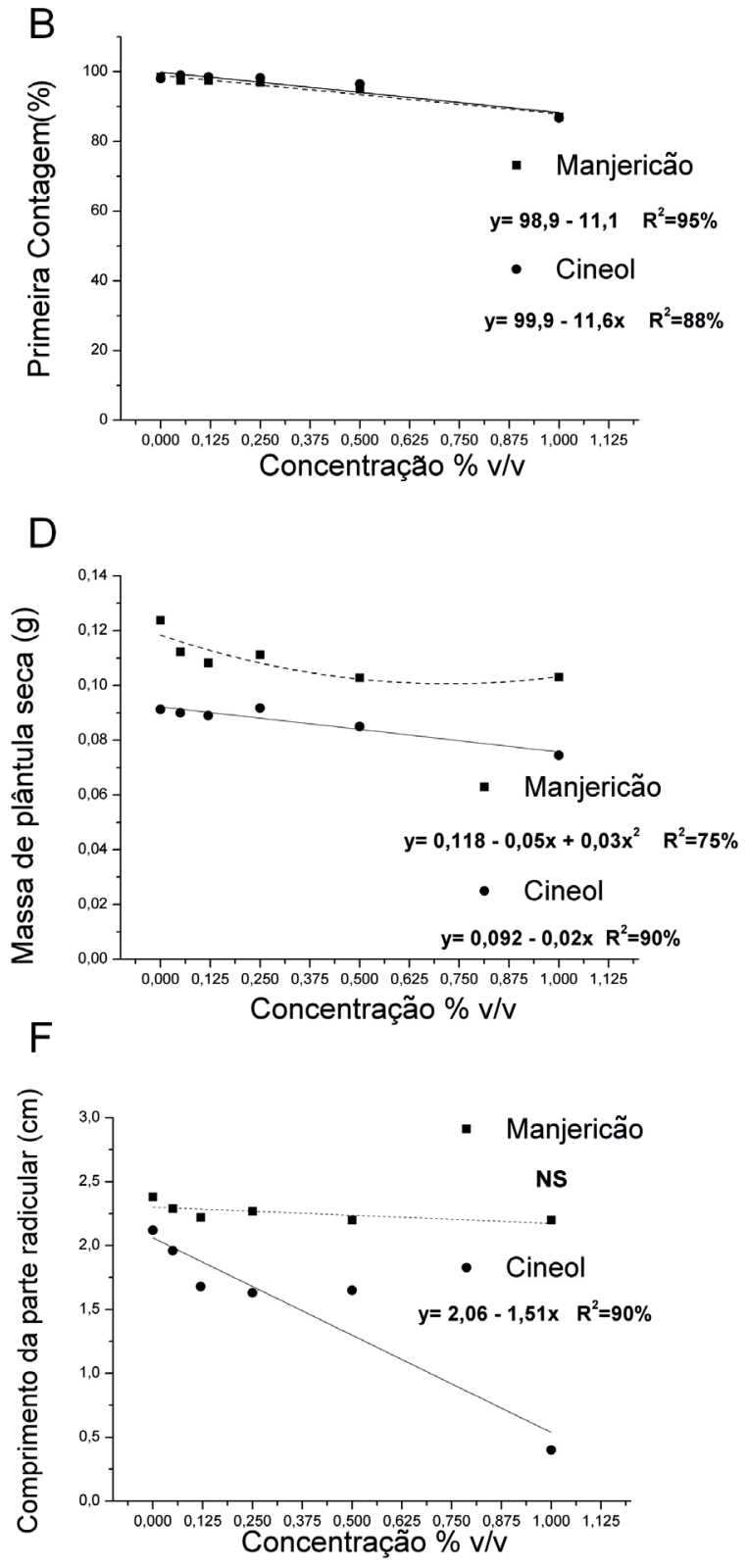

Cineol

Fonte: Elaboração dos autores.

\section{Conclusões}

Os óleos essenciais de capim-limão e alfavaca apresentaram potenciais alelopáticos sobre a germinação e o vigor de aquênios de alface que podem ser atribuídos aos conteúdos dos respectivos constituintes majoritários, citral e o eugenol, enquanto que o efeito alelopático do óleo essencial de manjericão é consequência do efeito conjunto de todos os componentes do mesmo, independente da metodologia de aplicação. 


\section{Agradecimentos}

Ao CNPq, CAPES e FAPEMIG pelo apoio financeiro e pela bolsa concedida.

\section{Referências}

ADAMS, R. P. Identification of essential oils components by gas chromatography/mass spectroscopy. $4^{\text {th }}$ ed. Carol Stream: Allured, 2007. 804 p.

ALVES, M. C. S.; MEDEIROS FILHO, S.; INNECCO, R.; TORRES, S. B. Alelopatia de extratos voláteis na germinação de sementes e no comprimento da raiz de alface. Pesquisa Agropecuária Brasileira, Brasília, v. 39, n. 11, p. 1083-1086, 2004.

BRASIL. Ministério da Agricultura, Pecuária e Abastecimento. Regras para Análise de Sementes. Ministério da Agricultura, Pecuária e Abastecimento. Secretaria de Defesa Agropecuária. Brasília, MAPA/ ACS, 2009. 395 p.

COITINHO, R. L. B. C.; OLIVEIRA, J. V.; GONDIM JÚNIOR, M. G.; CÂMARA, C. A. G. Persistência de óleos essenciais em milho armazenado, submetido à infestação de gorgulho do milho. Ciência Rural, Santa Maria, v. 40, n. 7, p. 1492-1496, 2010.

GOBBO-NETO, L.; LOPES, N. P. Plantas medicinais: fatores de influência no conteúdo de metabólitos secundários. Química Nova, São Paulo, v. 30, n. 2, p. 374-381, 2007.

GUIMARÃES, L. G. L.; CARDOSO, M. G.; SOUSA, P. E.; ANDRADE, J.; VIEIRA, S. S. Atividade antioxidante e antifúngica do óleo essencial da capim-limão e citral. Revista Ciência Agronômica, Fortaleza, v. 42, n. 2, p. 464-472, 2011.

GUIMARÃES， L. G. L.; CARDOSO, M. G.; ZACARONI, L. M.; LIMA, R. K.; PIMENTEL, F. A.; MORAIS, A. R. Influência de luz e temperatura na oxidação de óleo essencial de capim-limão (Cymbopogon citratus (DC) Stapf). Química Nova, São Paulo, v. 31, n. 6, p. 1476-1480, 2008.

HUSSAIN, A. I.; ANWAR, F.; SHERAZI, S. H. T.; PRZYBYLSKI, R. Chemical composition, antioxidant and antimicrobial activities of basil (Ocimum basilicum) essential oils depends on seasonal variations. Food Chemistry, Oxford, v. 108, n. 3, p. 986-995, 2008.

KRZYZANOWSKI, F. C.; VIEIRA, R. D.; FRANÇA NETO, J. B. Vigor de sementes: conceitos e testes. Londrina: ABRATES, 1999. 218 p.
LI, J.; LIU, X.; DONG, F.; XU, J.; LI, Y.; SHAN, W.; ZHENG, Y. Potential allelopathic effects of volatile oils from Descurainia sophia (L.) Webb ex Prantl on wheat. Biochemical Systematics and Ecology, Oxford, v. 39, n. 1, p. 56-63, 2011.

MAGUIRE, J. D. Speed of germination aid in selection and evaluation for seedling emergence and vigor. Crop Science, Madison, v. 2, n. 2, p. 176-177, 1962.

MIRANDA, C. A. S. F.; CARDOSO, M. G.; CARVALHO, M. L. M.; FIGUEIREDO, A. C. S.; NELSON, D. L. N.; OLIVEIRA, C. M.; GOMES, M. S.; ANDRADE, J.; SOUZA, J. A.; ALBUQUERQUE, L. R. M. Chemical composition and allelopathic activity of Parthenium hysterophorus and Ambrosia polystachya weeds essential oils. American Journal of Plant Sciences, Irvine, v. 5, n. 9, p. 1248-1257, 2014.

PEREIRA, C. A. M.; MAIA, J. F. Estudo da atividade antioxidante do extrato e do óleo essencial obtidos das folhas de alfavaca (Ocimum gratissimum L.). Ciência e Tecnologia de Alimentos, Campinas, v. 27, n. 3, p. 624632, 2007.

PIMENTEL, F. A.; CARDOSO, M. G.; SALGADO, A. P.; AGUIAR, P. M.; SILVA, V. F.; MORAIS, A. R.; NELSON, D. L. A convenient method for the determination of moisture in aromatic plants. Química Nova, São Paulo, v. 29, n. 2, p. 373-375, 2006.

ROSADO, L. D. S.; RODRIGUES, H. C. A.; PINTO, J. E. B. P.; CUSTODIO, T. N.; PINTO, L. B. B.; BERTOLUCCI, S. K. V. Alelopatia do extrato aquoso e do óleo essencial de folhas do manjericão "Maria Bonita" na germinação de alface, tomate e melissa. Revista Brasileira de Plantas Medicinais, Botucatu, v. 11, n. 4, p. 422-428, 2009.

SILVA, C. B.; SIMIONATTO, E.; HESS, S. C.; PERES, M. T. L. P.; SIMIONATTO, E. L.; WISNIEWSKI JÚNIOR, A.; POPPI, N. R.; FACCENDA, O.; CÂNDIDO, A. C. S.; SCALON, S. P. Q. Composição química e atividade alelopática do óleo volátil de Hydrocotyle bonariensis Lam (Araliaceae). Química Nova, São Paulo, v. 32, n. 9, p. 2373-2376, 2009.

SIMÕES, C. M. O.; SCHENKEL, E. P.; GOSMANN G.; MELLO, J. C. P.; MENTZ, L. A.; PETROVICK, P. R. Farmacognosia: da planta ao medicamento. 6. ed. Porto Alegre: UFRGS, 2007. 1104 p.

SOUZA FILHO, A. P. S.; GUILHON, G. M. S. P.; SANTOS, L. S. Metodologias empregadas em estudos de avaliação da atividade alelopática em condições de laboratório: revisão crítica. Planta Daninha, Viçosa, v. 28, n. 3, p. 689-697, 2010. 
SOUZA FILHO, A. P. S.; GUILHON, G. M. S. P.; ZOGHBI, M. G. B.; CUNHA, R. L. Análise comparativa do potencial alelopático do extrato hidroalcoólico e do óleo essencial de folhas de cipó-d'alho (Bignoniaceae). Planta Daninha, Viçosa, v. 27, n. 4, p. 647-653, 2009.

SOUZA FILHO, A. P. S.; SANTOS, R. A.; SANTOS, L. S.; GUILHON, G. M. P.; SANTOS, A. S.; ARRUDA,
M. S. P.; MUller, A. H.; ARRUDA, A. C. Potencial alelopático de Myrcia guianensis. Planta Daninha, Viçosa, v. 24, n. 4, p. 649-656, 2006.

VAN DEN DOOL, H.; KRATZ, D. J. A generalization of the retention índex system including liner temperature programmed gás-liquid partition chromatography. Jounal of Chromatography, v. 11, n. 1, p. 463-467, 1963. 
